Introduction to Nuclear Reactions 

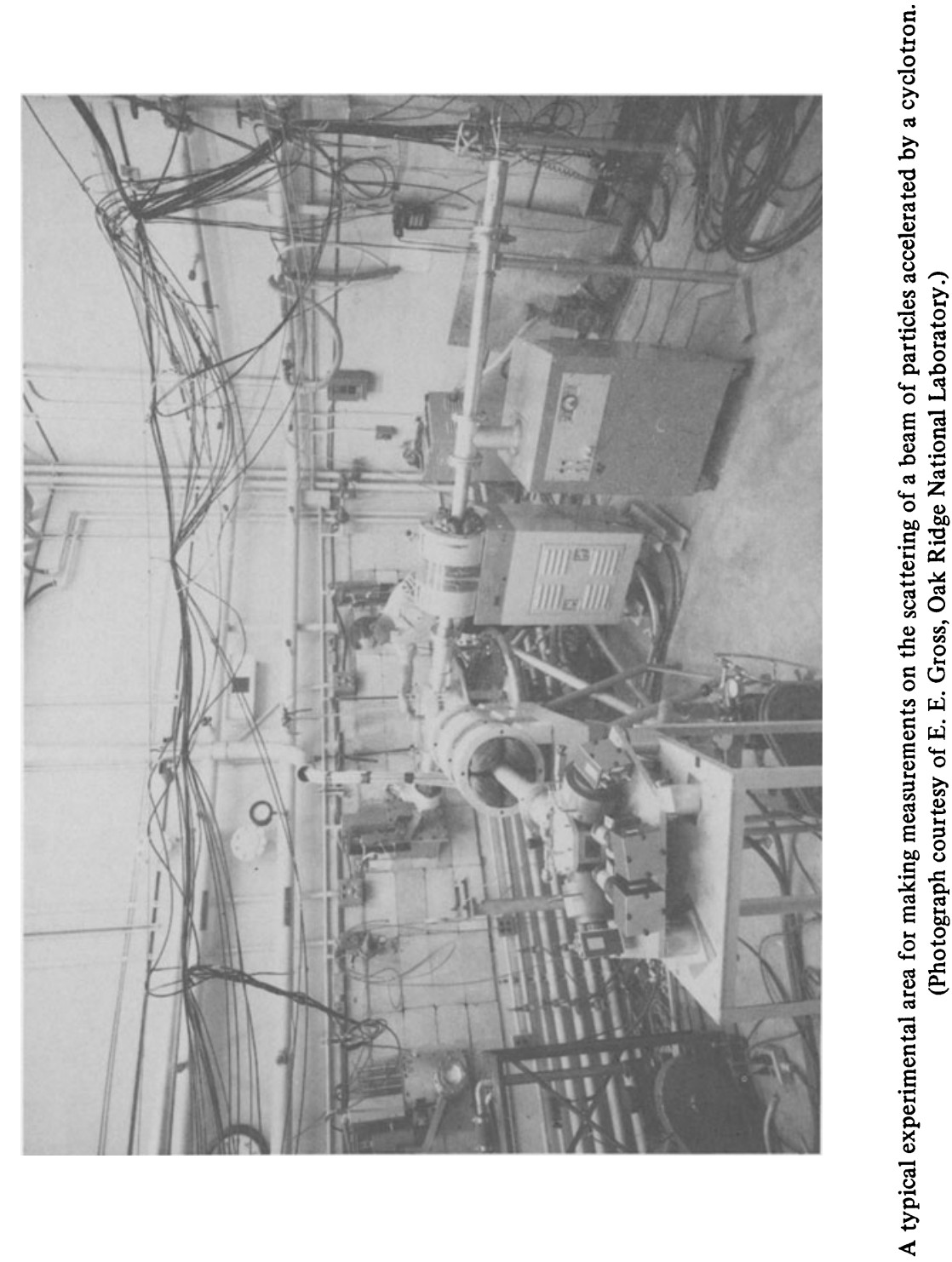


\section{INTRODUCTION TO NUCLEAR REACTIONS}

G. R. SATCHLER, MA, DSc(Oxon), FAPS

Oak Ridge National Laboratory

Oak Ridge, Tennessee 37831

SECOND EDITION

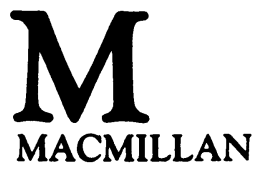


○) G. R. Satchler 1980, 1990

All rights reserved. No reproduction, copy or transmission of this publication may be made without written permission.

No paragraph of this publication may be reproduced, copied or transmitted save with written permission or in accordance with the provisions of the Copyright Act 1956 (as amended), or under the terms of any licence permitting limited copying issued by the Copyright Licensing Agency, 33-4 Alfred Place, London WC1E 7DP.

Any person who does any unauthorised act in relation to this publication may be liable to criminal prosecution and civil claims for damages.

First edition 1980

Second edition 1990

Published by

\section{MACMILLAN EDUCATION LTD}

Houndmills, Basingstoke, Hampshire RG21 2XS

and London

Companies and representatives

throughout the world

British Library Cataloguing in Publication Data

Satchler, G. R. (George Raymond)

Introduction to nuclear reactions.-2nd ed

1. Nuclear reactions

I. Title

$539.7^{\prime} 5$

ISBN 978-0-333-51484-9

ISBN 978-1-349-20531-8 (eBook)

DOI 10.1007/978-1-349-20531-8 


\section{Contents}

Preface to the Second Edition $\quad \mathrm{xi}$

Preface to the First Edition xiii

1. Some Background Information 1

1.1 Discovery of the nucleus 1

1.2 Constitution of the nucleus 2

1.3 The study of the nucleus by nuclear reactions 2

1.4 Some practical applications 4

1.5 The role of models 4

1.6 Conservation laws and symmetry principles 6

$\begin{array}{ll}1.7 \text { Some basic facts about nuclei } & 8\end{array}$

1.7.1 Mass, charge and binding energy $\quad 8$

$\begin{array}{ll}\text { 1.7.2 Size and radial shape } & 9\end{array}$

$\begin{array}{ll}\text { 1.7.3 Spins, parities and moments } & 10\end{array}$

$\begin{array}{ll}\text { 1.7.4 Excited states } & 12\end{array}$

$\begin{array}{ll}\text { 1.7.5 Time scales } & 15\end{array}$

1.7.6 Relativity and nuclear physics $\quad 16$

References 16

Exercises 17

2. Introduction to Nuclear Reactions 21

2.1 Introduction 21

2.2 The centre-of-mass coordinate system 22

2.3 Types of reaction 24

2.4 Energy and mass balance 26

2.5 Other conserved quantities 27

2.6 Cross-sections 28

2.7 Attenuation of a beam 30

2.8 Nuclear sizes from neutron scattering and a simple transmission experiment 31

2.9 A typical accelerator experiment 33 
2.10 Coulomb scattering and Rutherford's formula 34

$\begin{array}{ll}2.10 .1 \text { Classical derivation } & 35\end{array}$

2.10.2 Quantum and relativistic effects $\quad 39$

$\begin{array}{ll}2.10 .3 \text { Extended particles } & 40\end{array}$

2.10.4 Classical relations for Coulomb orbits $\quad 43$

2.11 Electron scattering $\quad 44$

2.12 Coulomb excitation $\quad 49$

$\begin{array}{ll}2.13 \text { Polarisation } & 50\end{array}$

2.14 Angular correlations $\quad 53$

2.15 Partial waves and the wave mechanics of scattering 54

2.16 Scattering of identical particles $\quad 59$

$\begin{array}{ll}2.17 & \text { Inverse reactions } \\ 2.18 & 60\end{array}$

2.18 Qualitative features of nuclear reactions 62

2.18.1 Compound nucleus formation and direct reactions $\quad 64$

2.18.2 Compound resonances $\quad 69$

2.18.3 Reaction times $\quad 71$

$\begin{array}{ll}2.18 .4 \text { Energy spectra } & 71\end{array}$

$\begin{array}{ll}2.18 .5 \text { Branching ratios } & 73\end{array}$

2.18.6 Importance of direct reactions $\quad 74$

2.18.7 Characteristic angular distributions $\quad 74$

$\begin{array}{ll}2.18 .8 \text { Coulomb effects } & 77\end{array}$

2.18.9 Giant resonances and strength functions $\quad 78$

$\begin{array}{ll}2.18 .10 \text { Cross-section fluctuations } & 79\end{array}$

2.18.11 Strong and weak absorption; diffraction and the

$\begin{array}{ll}2.18 .12 \text { Some characteristics of heavy-ion reactions } & 81\end{array}$

$\begin{array}{ll}\text { References } & 83\end{array}$

$\begin{array}{ll}\text { Exercises } & 85\end{array}$

3. Elementary Scattering Theory $\quad 89$

$\begin{array}{lll}3.1 & \text { Form of the wave function } & 89\end{array}$

3.1.1 The incident wave $\quad 90$

3.1.2 Laboratory and centre-of-mass systems $\quad 92$

$\begin{array}{ll}3.1 .3 \text { Internal states } & 93\end{array}$

3.1.4 The scattered waves $\quad 94$

$\begin{array}{ll}3.2 \text { Differential cross-sections } & 95\end{array}$

3.3 The Schrödinger equation 96

3.3.1 Coupled equations form of the Schrödinger equation 97

3.3.2 Integral form of the Schrödinger equation for scattering
by a potential

3.3.3 The Born and the distorted-wave Born approximations $\quad 100$

$\begin{array}{ll}\text { 3.3.4 Integral equation for a general collision } & 102\end{array}$

$\begin{array}{lll}3.4 & \text { Partial waves } & 104\end{array}$

3.4.1 Significance of partial waves $\quad 104$

$\begin{array}{ll}\text { 3.4.2 Partial wave expansions } & 106\end{array}$ 
3.4.3 Ingoing and outgoing waves 107

3.4.4 Scattering matrix and phase shifts 109

3.4.5 Phase shifts for potential scattering 110

3.4.6 Partial wave expression for scattering amplitudes $\quad 112$

3.4.7 Effects of Coulomb forces 113

3.4.8 Partial wave expressions for cross-sections 115

3.4.9 Integrated cross-sections $\quad 115$

3.4.10 Limits on partial cross-sections $\quad 116$

3.5 Total cross-section and the optical theorem 118

3.6 Penetration and reflection at potential barriers 120

3.6.1 Reflection by an absorptive region $\quad 120$

3.6.2 Coulomb barriers 121

3.6.3 Transmission across a rounded barrier 123

3.7 Behaviour of cross-sections near threshold 124

3.8 Collisions with spin: general theory 126

3.8.1 Spins and channel spin $\quad 126$

3.8.2 Collision channels with spins $\quad 129$

3.8.3 The scattering wave function and the scattering matrix $\quad 129$

3.8.4 Cross-sections and inverse reactions $\quad 130$

3.9 $R$-matrix and boundary-matching theories 131

3.10 Classical and semi-classical descriptions of scattering 132

3.10.1 Classical elastic scattering of particles 133

3.10.1.1 Deflection function, orbits and cross-sections $\quad 134$

3.10.1.2 Rainbows and glories 137

3.10.2 Semi-classical treatments $\quad 139$

3.10.2.1 The WKB approximation 140

3.10.2.2 The eikonal approximation $\quad 141$

3.10.3 Diffraction and the effects of strong absorption $\quad 143$

3.11 The impulse approximation $\quad 146$

$\begin{array}{ll}\text { References } & 148\end{array}$

Exercises $\quad 150$

4. Models of Nuclear Reactions 153

4.1 Partial waves and strong absorption $\quad 154$

4.1.1 Sharp cut-off model $\quad 154$

4.1.2 Comparison with experiment 155

4.1.3 Smooth cut-off models $\quad 155$

4.1.4 The nuclear radius and surface thickness $\quad 157$

4.2 Effects of the Coulomb field 158

4.3 Diffraction models and strong-absorption scattering 161

4.3.1 Fraunhöfer diffraction $\quad 161$

4.3.2 Fresnel diffraction $\quad 165$

4.3.3 Relation between diffraction and partial wave descriptions 166

4.4 Strong-absorption models for inelastic scattering 167

$\begin{array}{ll}\text { 4.4.1 Adiabatic approximation } & 167\end{array}$ 
4.4.2 Fraunhöfer diffraction $\quad 170$

4.4.3 Applications of the Fraunhöfer model 172

4.4.4 Coulomb effects and Coulomb excitation $\quad 172$

4.4.5 Extensions of the model $\quad 174$

4.4.6 Strong absorption and other direct reactions $\quad 174$

$\begin{array}{ll}\text { 4.5 The optical model for elastic scattering } & 175\end{array}$

$\begin{array}{ll}4.5 .1 \text { Introduction } & 175\end{array}$

4.5.2 'Echoes' in neutron cross-sections $\quad 177$

4.5.3 Average interaction potential for nucleons 181

4.5.4 Energy dependence of the potential 183

4.5.5 Spin-orbit coupling $\quad 185$

4.5.6 Average potentials for composite projectiles 186

4.5.7 Imaginary potentials and absorption $\quad 187$

4.5.8 Analyses of scattering experiments $\quad 189$

4.5.8.1 Nucleon scattering $\quad 190$

4.5.8.2 Scattering of composite particles $\quad 194$

$\begin{array}{lll}4.6 & \text { The meaning of a nuclear radius } & 198\end{array}$

$\begin{array}{lll}4.7 & \text { Direct reactions } & 201\end{array}$

4.7.1 A semi-classical model 202

4.7.2 Perturbation theory and the Born approximations 204

4.7.2.1 Plane-wave Born approximation 204

4.7.2.2 Distorted-wave Born approximation 206

$\begin{array}{ll}\text { 4.7.3 Inelastic scattering } & 210\end{array}$

4.7.4 Stripping and pick-up reactions $\quad 212$

4.7.4.1 Deuteron stripping and pick-up 212

4.7.4.2 Other stripping and pick-up reactions $\quad 214$

$\begin{array}{ll}\text { 4.7.5 Knock-out reactions } & 215\end{array}$

4.7.6 Multi-step processes and strong coupling 218

$\begin{array}{lll}4.8 & \text { Compound nucleus resonances } & 223\end{array}$

4.8.1 Simple theory of a resonant cross-section $\quad 226$

4.8.2 More formal theory of a resonance 229

4.8.2.1 Single isolated resonance $\quad 230$

4.8.2.2 The wave function at resonance $\quad 234$

4.8.2.3 Time delay and interferences 235

4.8.3 Resonances with charged particles $\quad 237$

4.8.4 Angular momentum and spin $\quad 237$

4.8.5 Limits on the cross-sections 238

4.8.6 Overlapping resonances $\quad 238$

4.8.7 Resonances as poles in the scattering matrix 239

4.8.8 Isobaric analogue resonances $\quad 239$

4.9 Continuum or statistical theory of the compound nucleus 242

4.9.1 Statistical model for formation and decay of the compound nucleus 
4.9.2 The evaporation model for decay of the compound nucleus

4.9.3 Pre-equilibrium decays

4.9.4 Fluctuation phenomena

4.9.5 Direct reactions

4.10 The optical model at low energies and the neutron strength function

4.11 Nuclear reactions with light ions of high energies

4.12 Reactions between heavy ions

A2 Angular momentum coupling and systems composed of two or more parts

A3 Spherical harmonics

A4 Example 1: radioactive decay of a nucleus

A5 Example 2: formation of a compound nucleus and statistical weights

References

Appendix B Transformations between LAB and CM Coordinate Systems 297

B1 Elastic scattering

B2 Non-elastic collisions

B3 Special cases

Reference

302

Appendix C Some Useful Data 303

C1 Prefixes $\quad 303$

$\begin{array}{ll}\text { C2 Physical constants } & 303\end{array}$

$\begin{array}{ll}\text { C3 Rest masses } & 304\end{array}$

C4 Related quantities $\quad 304$

$\begin{array}{ll}\text { C5 The elements } & 305\end{array}$

Appendix D Penetration of Potential Barriers and the Fusion of

$\begin{array}{ll}\text { Very Light Nuclei } & 307\end{array}$

$\begin{array}{lr}\text { Solutions to Exercises } & 310\end{array}$

Index 


\section{Preface to the Second Edition}

The past decade has seen a remarkable growth in the extent and variety of experiments being done on nuclear reactions. The range of energies available has increased by two orders of magnitude. Because of the rapid expansion of heavyion science, the number of projectiles in use is very much greater and now includes nuclei as heavy as those of uranium atoms. However, the basic physical principles and techniques involved in the description of these reactions has remained unchanged, although the emphasis may have shifted to some degree. For example, the application of semi-classical ideas became more extensive with the increased interest in heavy-ion reactions, while relativistic considerations became more important as the energy increased.

These advances have resulted in some changes being made in the text, together with some modernisation of the references. Again, the reader is urged to consult review journals and the proceedings of recent conferences for the latest developments. The many experimental examples shown in the figures have not been changed; these were mostly drawn from work done at energies lower than those currently available. Nonetheless, the features illustrated remain relevant at these higher energies.

The opportunity has been taken to correct some misprints, errors, omissions and obscurities that were present in the original. I am indebted to numerous people for bringing many of these to my attention, especially R. C. Johnson, S. Kobayashi and A. G. Tibell. 


\section{Preface to the First Edition}

This book is aimed primarily at the undergraduate or beginning graduate student, although I believe others will also find it useful. The specialist from another field may find here a summary of the present situation in our understanding of nuclear-reaction phenomena. The established nuclear physicist may find reading it to be helpful in refreshing his memory about areas in which he is not currently working himself.

Chapters 1 and 2 are intended to provide an overview of the subject which can be readily understood by the novice. They also serve as an introduction to the somewhat more serious remainder. Chapter 3 reviews scattering theory with emphasis on the underlying physical ideas. It also provides schematic entrées to the more advanced topics. (There are other excellent texts available which expound these more formal and mathematical aspects of scattering theory.) The discussion is not specific to nuclei, so that Chapter 3 may serve equally well as an introduction to the theory of atomic and molecular collisions. The physical models which have been developed to account for the various aspects of nuclear reaction phenomena are described in more detail in Chapter 4, which is the largest section of the book. I believe that this arrangement enables the book to cater to the needs of a variety of readers without sacrificing any coherence of the presentation as a whole.

Some acquaintance with quantum mechanics is assumed, but not to any great depth. In general, the emphasis here is on the word 'introduction' in the title. There are a number of books and many review articles which treat various parts of the subject in detail and at a higher level; some of these are referred to in the text and are listed in the references at the end of each chapter. Many references are made also to original research papers in the belief that the reader should be encouraged to dip into these other sources of material even if generally they do seem to be more technically advanced than he needs.

Nuclear physics is still very much a living, developing field of study. Consequently any book such as this one is in danger of being obsolescent in some res- 
pect as soon as it appears. (This is particularly liable to apply to the descriptions of heavy-ion reactions). This is another reason to urge the reader to supplement the material presented here by resorting freely to the current literature such as review journals and books, and reports of the proceedings of conferences.

The instrumental, experimental and technological aspects of studying nuclear reactions are scarcely mentioned in the present volume; the purpose here is to understand the results of measurements rather than to describe how they are made. There are a number of good books available which address themselves to experimental problems and techniques; we mention in particular Atomic Nuclei and Their Particles by E. J. Burge (Oxford University Press, 1977) and, at a more advanced level, the excellent Techniques in Nuclear Structure Physics by

J. B. A. England (Halsted, New York, 1974).

The first draft of this book was written in the summer of 1970 while the author was a guest of the Aspen Center for Physics, Colorado. I am indebted to the Center for providing a climate so conducive to this achievement. Various sections of the text were read by D. M. Brink, K. T. Hecht and D. K. Scott; I am grateful for their helpful comments. I am also grateful to the many colleagues who have permitted me to reproduce their illustrations here. Finally, I am indebted to Mrs. Althea Tate for efficiently, patiently and cheerfully typing and retyping the manuscript. 